\title{
A Qualitative Analysis of Patient-Related Factors Associated With Implantable Cardioverter Defibrillator Acceptance
}

\author{
Amber E. Johnson (D) - Yamira K. Bell • Megan E. Hamm • \\ Samir F. Saba · Larissa Myaskovsky
}

Received: April 9, 2020 / Published online: May 31, 2020

(C) The Author(s) 2020

\begin{abstract}
Introduction: Patient-related factors determining implantable cardioverter-defibrillator (ICD) use for primary prevention of sudden cardiac death in patients with cardiomyopathy have not been well explored. To assess race and sex differences regarding ICD preferences in this patient population, we sought to analyze a diverse cohort of patients with heart failure (HF) with reduced ejection fraction.
\end{abstract}

Methods: We conducted qualitative interviews of 28 adults with severe HF and either (1) an ICD or (2) no ICD. Interviews were recorded,

Digital Features To view digital features for this article go to https://doi.org/10.6084/m9.figshare.12311384.

Electronic supplementary material The online version of this article (https://doi.org/10.1007/s40119020-00180-9) contains supplementary material, which is available to authorized users.

A. E. Johnson $(\varangle) \cdot$ M. E. Hamm · S. F. Saba Internal Medicine, University of Pittsburgh, Pittsburgh, PA, USA

e-mail: johnsonae2@upmc.edu

Y. K. Bell

School of Medicine, University of Pittsburgh, Pittsburgh, PA, USA

L. Myaskovsky

Internal Medicine and Psychiatry, University of Pittsburgh, and Center for Health Equity Research and Promotion, Veterans Affairs Pittsburgh

Healthcare System, Pittsburgh, PA, USA transcribed, and coded using an inductively developed codebook by independent investigators. Coding was fully adjudicated and transcripts were reviewed to identify themes.

Results: We recruited patients between $12 / 2015$ and $06 / 2017$, primarily from the outpatient cardiology clinic $(24 / 28=86 \%)$. Half were women (50\%) and 13/28 (46\%) were black. Eight did not have an ICD. Neither race nor sex was associated with ICD. Four themes emerged: (1) HF requiring an ICD is profoundly disruptive to patients' lives; (2) patients had positive, yet unrealistic opinions of ICDs; or (3) Patients had negative/ambivalent opinions of ICDs; (4) medical decision-making included aspects of shared decision-making and informed consent. Conclusions: Patients without ICDs perceived less benefit from ICDs and had less decision support. Participants viewed conversations with providers as insufficient. Needed interventions include the development and validation of processes for informed decisions about ICDs.

Keywords: Implantable defibrillator; Practice guidelines; Shared decision-making 


\section{Key Points}

Why carry out this study?

Patients with severe heart failure face many decisions about their care.

It is unknown how patients feel when deciding about ICD implantation.

What was learned from this study?

Some patients with ICD have either unrealistic expectations or negative opinions of ICDs.

Accepting ICD implantation requires informed consent and patient decision support.

Current communication may be insufficient to explain ICD implantation to patients.

\section{INTRODUCTION}

Implantable cardioverter defibrillators (ICDs) are indicated for patients who have heart failure (HF) with reduced ejection fraction as primary prevention of sudden death from ventricular arrhythmia and constitute an important addition to guideline-based therapy [1-5]. Patients with severely weak hearts are at elevated risk for the development of cardiac arrhythmia or sudden death; therefore, the devices monitor a patient's heart rhythm and deliver a defibrillation if a deadly rhythm is detected. In patients with severe HF, primary prevention ICDs are indicated to prevent sudden cardiac arrest, but are not curative. Many studies have demonstrated underutilization of ICDs in eligible patients [6-11]. Evidence demonstrates disparities by race and sex in ICD utilization [12, 13], where women and minorities are less likely to receive a primary prevention ICD $[8,13,14]$. We previously demonstrated race and sex underutilization of ICDs [15] and have shown that these troubling race and gender disparities persist [16] despite the published guidelines for sudden cardiac death prevention, according to which ICDs are indicated in eligible patients, regardless of race or sex [17-19].

Data suggest that underutilization of indicated therapies could be secondary to patientspecific barriers to accepting care [20]. Patientderived factors that may impact ICD utilization could include healthcare beliefs and preferences, race/ethnicity, culture, or education [20]. Data from other clinical populations have shown that differences in patient beliefs are correlated with the patients' race/ethnicity and may help to explain differences in procedure acceptance [21]. Furthermore, data suggest that decisions about ICD implantation may be preference-sensitive $[22,23]$, meaning that they vary based on an individual's values. Of note, patients with severe cardiomyopathy face many possible therapeutic options including complicated medication regimens, device implantation, and possible heart transplantation. Thus, understanding patients' perceptions as they interface with a complex health condition is essential to engage them in medical decisionmaking about ICDs.

To date, few studies have examined patient beliefs and preferences regarding acceptance of ICD implantation and none have focused on race or sex differences in ICD acceptance. To better understand the mechanisms underlying ICD acceptance, we conducted a qualitative analysis of a diverse group of patients who qualify for primary prevention ICD. We used indepth, semi-structured patient interviews to assess the patient's points of view. We hypothesized that patients with ICD would have perceptions that differ from those who had declined ICD placement, thus we assessed a diverse group of patients to determine the relationship of race, sex, medical decisionmaking, value systems, and experiences with ICD decision-making. Notably, some patients with severe cardiomyopathy are eligible for cardiac resynchronization therapy if additional clinical criteria are met. However, indications of and consideration for advanced therapies beyond primary prevention ICD becomes increasingly nuanced and complex and was therefore beyond the scope of this study. 


\section{METHODS}

\section{Participant Selection and Setting}

We recruited patients from the inpatient cardiology service at UPMC Presbyterian Hospital, a large academic tertiary care center in Pittsburgh, Pennsylvania, USA, and from its affiliated general and subspecialty cardiology clinics. We used the electronic health record to screen patients for eligibility. Inclusion criteria were: age 18 years or older, presence of HF diagnosis, and ejection fraction of $35 \%$ or less by echocardiogram. We excluded patients who were unable to provide informed consent, or had no working telephone number, or with significant cognitive impairment. We also excluded patients with either ventricular arrhythmia or an indication for resynchronization therapy to ensure all patients had an indication for primary prevention ICD implantation. We used purposeful stratified sampling to include men and women and those with and without ICD. We limited the study to black and white patients because most of the prior studies have focused on black-white race differences and due to relative lack of other racial groups in our hospital system. Medical approval from the recruitment site was not required, however clinicians directly caring for eligible patients granted permission for investigator approach. After an introduction from the clinician, potential participants were approached by the study investigator either at the bedside if inpatient, or in the examination room if at a clinic appointment. All participants completed informed consent prior to enrollment, and were compensated $\$ 40$ for study participation. The authors have received approval from the University of Pittsburgh institutional review board (PRO16050348). This study was performed in accordance with the Helsinki Declaration of 1964, and its later amendments.

\section{Data Collection}

Using semi-structured qualitative interviews, we gathered participant perspectives on ICD implantation and device acceptance. This approach allowed us to more thoroughly capture patient views on ICDs. It enabled participants to freely express their thoughts, experiences, and opinions. The qualitative questions included open-ended questions to assess the history and progress of the patients' heart problems, concerns about ICD, thoughts about the discussion surrounding ICD, and lifestyle concerns. Interviewers were trained to probe and ask clarifying questions whenever answers to the original questions were vague or needed further explanation (see Table S1). We also obtained participant demographic information (e.g., race, sex, age, etc.) via self-report during the telephone interview.

The open-ended questions were administered over the phone following a series of related survey questions. Study questions were pilot tested in a previous study [24]. Interviews were conducted by a staff of survey professionals at the University of Pittsburgh Center for Social and Urban Research, and were then transcribed verbatim. We made audio recordings using an encrypted digital recording device, which were then transcribed.

Qualitative analysis uses thematic saturation, which is the point at which additional data collection produces no new information [25] to determine adequate sample size. We reached saturation across all groups.

\section{Codebook Development}

During its development, the code structure was reviewed four times by the coding team (lead by AJ) for logic and breadth. The review process included inductively adding and reconstructing codes reflecting topics and themes that arose in the data as new insights emerged.

\section{Coding and Analysis}

We analyzed the transcribed data with common coding techniques for qualitative data using ATLAS.ti software, version 7 (Scientific Software Development GmbH, Berlin, Germany). Using this software, the coders read each sentence and assigned a code to each meaningful phrase, 
sentence, or group of sentences. Coders were blinded to participant race and sex during initial coding. Two investigators (AJ and $\mathrm{MH}$ ) individually coded all interview transcripts, then met to review all codes. All coding disagreements were adjudicated to full agreement, after which three investigators conducted a thematic analysis (AJ, YB, and $\mathrm{MH})$. We assessed differences in ICD acceptance by sex and race using Student's $t$ test for continuous variables and Fisher's exact tests for categorical variables. We also assessed mean age by race/sex groupings using the analysis of variance. A $p$ value of 0.05 was considered statistically significant. We performed statistical analyses using Stata version 15 (College Station, TX, USA).

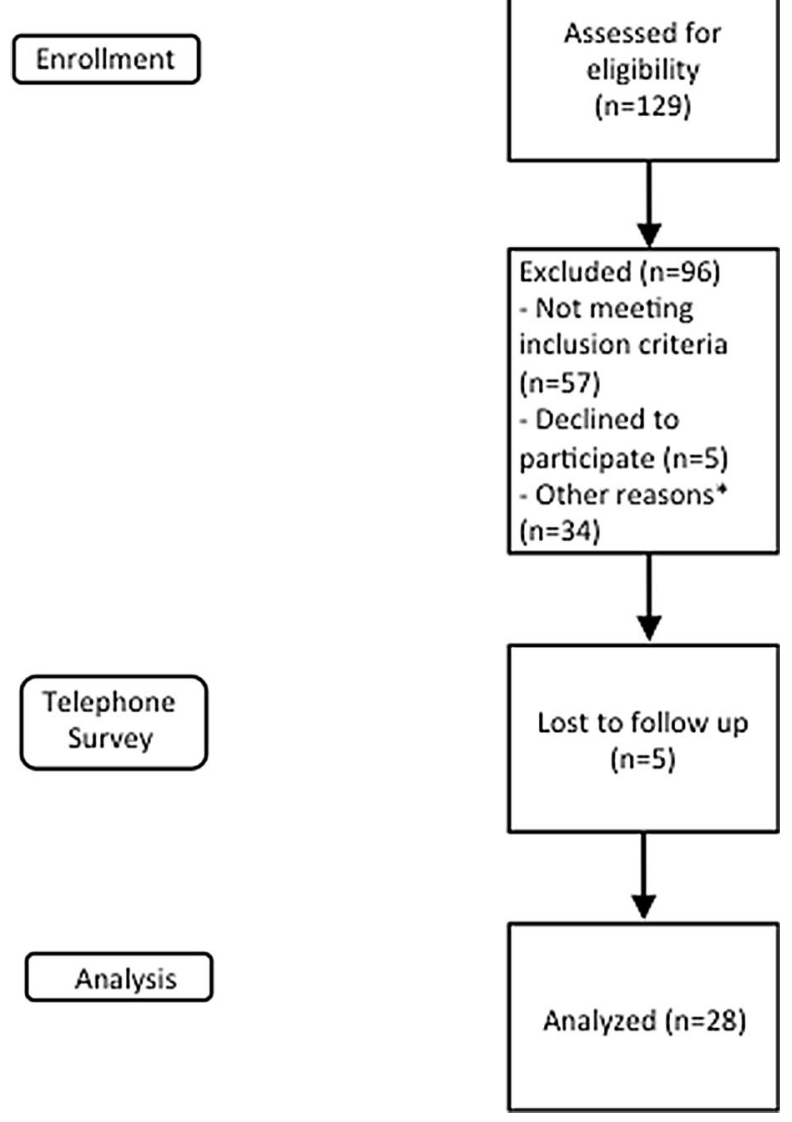

Fig. 1 Patient flow diagram. (Asterisk) Other reasons include missing multiple clinic appointments, therefore unable to be recruited from clinic, or otherwise unavailable for recruitment

\section{RESULTS}

\section{Participant Characteristics}

We successfully recruited 28 participants between 12/2015 and 06/2017 (see Fig. 1). Nearly all participants $(24 / 28=86 \%)$ were from the outpatient cardiology clinic. Half of the participants were women $(50 \%)$ and 13 of 28 (46\%) were African American. Eight participants had declined ICD implantation and did not have a device in place. Of those with ICD, the range of implantation date was April 2007-June 2017. Days between implant to study enrollment was $12-3722$. Table 1 shows descriptive statistics for all 28 participants. Mean age of the cohort was 59.3 years (standard deviation $=15.0$ ). There was no difference in age by ICD status. However, we found a statistically significant difference in age across sex/race groups for the overall cohort $(F=4.09$, $p=0.03)$, which was driven by the younger age of black participants compared to white participants $(F=8.12, p=0.01)$. There was no sex difference for age. We found no race or sex differences for education, income, employment, having children, or marital status. Neither race nor sex was significantly associated with ICD acceptance.

\section{Coding and Themes}

After coding the transcripts, we calculated kappa scores to assess inter-coder reliability; the mean kappa was 0.72 . No new codes emerged after coding the 12th interview. We generated 18 unique codes with which we labeled the 28 transcripts a total of 541 times. We then organized participant's comments into four broad themes. To establish corroboration, a process of theme re-evaluation to better establish a valid framework, and to reduce thematic inconsistencies, we presented at a departmental conference. An expert panel reviewed the themes, which we then revised for further clarity. 
Table 1 Descriptive characteristics

\begin{tabular}{|c|c|c|c|c|c|c|c|c|c|}
\hline \multirow[t]{2}{*}{ Demographic, $n$ (\%) } & \multicolumn{3}{|l|}{ Race } & \multicolumn{3}{|l|}{ Sex } & \multicolumn{3}{|l|}{ ICD } \\
\hline & $\begin{array}{l}\text { White } \\
n=15\end{array}$ & $\begin{array}{l}\text { Black } \\
n=13\end{array}$ & $p$ value & $\begin{array}{l}\text { Male } \\
n=14\end{array}$ & $\begin{array}{l}\text { Female } \\
n=14\end{array}$ & $p$ value & $\begin{array}{l}\text { Yes } \\
n=20\end{array}$ & $\begin{array}{l}\text { No } \\
n=8\end{array}$ & $p$ value \\
\hline Mean age in years (SD) & $\begin{array}{l}66.1 \\
\quad(12.6)\end{array}$ & $\begin{array}{l}51.4 \\
\quad(14.0)\end{array}$ & 0.01 & $\begin{array}{l}59.9 \\
\quad(13.4)\end{array}$ & $\begin{array}{l}58.6 \\
\quad(16.9)\end{array}$ & 0.81 & $\begin{array}{l}60.6 \\
(15.7)\end{array}$ & $\begin{array}{l}55.8 \\
\quad(13.2)\end{array}$ & 0.45 \\
\hline White race & - & - & - & $8(57.1)$ & $7(50)$ & 0.71 & $10(50)$ & $5(62.5)$ & 0.55 \\
\hline Male sex & $8(53.3)$ & $6(46.2)$ & 0.71 & - & - & - & $10(50)$ & $4(50)$ & 1.0 \\
\hline $\begin{array}{l}\text { Educational level }=\text { completed } \\
\text { high school or more }\end{array}$ & $\begin{array}{l}14 \\
(93.3)\end{array}$ & $\begin{array}{l}10 \\
(76.9)\end{array}$ & 0.31 & $\begin{array}{l}12 \\
(85.7)\end{array}$ & $\begin{array}{l}12 \\
(85.7)\end{array}$ & 1.0 & $18(90)$ & $6(75)$ & 0.56 \\
\hline Income $<\$ 24,999$ & $6(40)$ & $6(46.1)$ & 0.74 & $6(42.9)$ & $6(42.9)$ & 1.0 & $10(50)$ & $2(25)$ & 0.40 \\
\hline Unemployed & $\begin{array}{l}10 \\
(66.7)\end{array}$ & $8(61.5)$ & 1.0 & $\begin{array}{l}10 \\
(71.4)\end{array}$ & $8(57.1)$ & 0.43 & $12(60)$ & $6(75)$ & 0.67 \\
\hline Has children & $8(53.3)$ & $7(53.8)$ & 0.40 & $6(42.9)$ & $7(50)$ & 0.08 & $14(70)$ & $7(87.5)$ & 0.63 \\
\hline Married & $7(46.7)$ & $5(38.5)$ & 0.66 & $5(35.7)$ & $7(50)$ & 0.45 & $7(35)$ & $5(62.5)$ & 0.23 \\
\hline
\end{tabular}

$S D$ standard deviation

\section{Theme 1: Being at a Stage of HF Requiring an ICD is Profoundly Disruptive to Patients' Lives}

Irrespective of ICD status, patients described being symptomatic from cardiomyopathy prior to being told about their candidacy for ICD placement. Participants described needing advanced care or additional services due to the severity of their HF presentation. For example, patients described being referred from their local hospitals to specialists at our tertiary care center. Some were listed for transplant. Notably, when stratified by sex, we found that codes describing symptoms and severity of their HF presentation were more common among women than men (coded 33 times versus 24 times).

As an example, one participant with an ICD suggested that because her condition was so poor, she was under the impression that the ICD was necessary.

"Oh, it was bad. I had gained some weight and was having trouble breathing, moving, everything. And I just thought it had been from gaining the weight until I was unable to breathe after taking some medication one night, and then suffered through the night, and then the next day, called my daughter to take me to the emergency room, and that's when we discovered the congestive heart failure... I just decided [the ICD] needed to be done." White woman with ICD.

Participants described having had limited healthcare interactions prior to their HF diagnosis. They described wanting to prevent HF disease progression. Patients valued their lives and hoped for the resumption of a normal quality of life. These aspects were reflected when discussing expectations, hopes, and concerns regarding ICD implantation.

"I just wanted to get it... I wanted to stay alive." White woman with ICD

Participants dichotomized their options as either receiving the ICD or facing death. Because some patients felt that it was important to prolong their lives, the desire to live factored heavily in their decision-making process, especially among participants with ICDs. We found that the code representing the desire to prolong life was three times more common in people 
with ICD than those without (coded 27 times versus nine times). For those with an ICD, the device was viewed as a means to improve survival, as in the following example.

"But I was tired, and I was a little on the depressed side because you're thinking about your life and what quality are you going to have and you just feel like maybe your life's over-I feel like there's a lot of things to do, and I haven't accomplished maybe a lot of things that I'd like to do. You know, I'd like to just live a little bit more. You know, nobody wants to go. Even though I'm 73." White woman with an ICD

On the contrary, for some without an ICD, survival seemed less certain:

"It's getting worse and I can't get better. There's no cure." White woman without an ICD

Among participants with ICDs, the device was viewed as either a temporary treatment to prevent disease progression or as a therapeutic option prior to heart transplant. Of the 18 times this code was applied, 17 were for transcriptions from participants with ICDs. Only one participant without ICD expressed comments regarding the device as a means to prevent disease progression, as expressed in the following quote.

“They told me if my heart didn't come back on its own or if medicines or whatever couldn't - like in three months, then there might be a need for some type of either a heart transplant or an ICD..." White woman without an ICD

Theme 2: Some Patients Had Positive, But at Times Unrealistic, Opinions of ICDs Some participants attributed unrealistic, curative qualities to primary prevention ICDs. Participants with this view perceived the ICD as a device to improve quality of life or cardiac function. They felt that the ICD was a necessary component of the best cardiac care. Subjects upholding this perception were focused on the hope of feeling better, rather than the prevention of cardiac arrhythmia. Of the 37 times the transcripts were coded as reflecting a positive view of ICDs, 31 were in participants with ICD. Patients who had declined ICD implantation did not express personal benefit from ICD or did not view the ICD as positive or curative.

In the following example, one woman describes how the ICD was a necessary step to being able to take care of herself and her family.

"We discussed how they had hoped it would get my heart back to where it was, so that I could go back to work, raise my son, do most of the things I had done prior to that." White woman with an ICD

The code for positive views regarding ICD was used more frequently among white participants compared with black ones (coded 24 times versus 13). For example, in the following quote, a white woman describes how she was led to believe that the ICD would help her to feel better.

"And they said, "you're going to feel good after a while, give it a chance. You're going to find you'll feel a lot better." White woman with ICD

\section{Theme 3: Some Patients Had Negative or Ambivalent Opinions of ICDs}

Both ICD accepters and non-accepters voiced concerns, including worry about generator change (battery replacement). They described concerns about risks of the procedure such as infection or other complications. Lifestyle concerns included having a foreign device inside their bodies, though relatively few people described major lifestyle limitations that would discourage a patient from accepting the ICD.

A negative lifestyle concern is described by the following quote.

"...what if the battery was dying or was going dead and you have to have surgery again to have another one put in. I don't like that, I don't like that idea." White woman without ICD.

Participants without ICDs expressed a lack of trust of their physician or the medical system as 
it related to deciding about getting an ICD implanted, as in the following example.

\section{"Along the way, I have discovered there's really not a whole lot they know about very much. It's a bunch of guesswork... there's a lot more they don't know than what they know." White man without ICD}

Although some participants did not describe abject negative feelings toward the ICD, they did express feelings of ambivalence. In the following example, one woman describes the difficulty she faced in deciding if ICD placement was right for her.

"I've had this discussion with many heart doctors. I have a team of doctors. Every one of them are pushing for ICD, because they say it will save my life... And they're telling me I really don't have any options. So an ICD is just to shock my heart back, but it's not going to help me. So I don't really understand... what am I supposed to do? I mean it's my decision. I'm not suicidal. But I don't want to live like this." White woman without ICD.

\section{Theme 4: Medical Decision-Making Included Elements of Shared Decision-Making and Informed Consent}

Participants described how they decided for or against device implantation, stating that conversations with their doctor were insufficient to accurately educate them about how ICDs work, their indications, and risks and benefits. Participants wanted to learn more about ICDs in the context of their healthcare decisions. The following quote is from a woman who had a misunderstanding of the purpose of her device.

"Well, he explained the procedure and everything, and then told me what they were going to do and how it would help my heart. Because I think my injection fraction was really low, you know, that I would feel better. That more or less everything would be better, you know, once I had this put in. Because at that time, I was feeling pretty rough." $\sim$ White woman with ICD

Deciding about ICD implantation usually requires trustful conversations between providers and patients. Mistrust of the medical system was commonly described. Participants without ICDs recalled negative medical interactions, which could further erode trust. Patients also expressed a lack of decision support. Yet they also expressed feeling that their physician had made the decision to place the ICD and that the patient had no choice in the matter. Similarly, black participants more often described feeling persuaded to get an ICD compared to white participants. The experience of having the physician decide about ICD placement was described 23 times among participants with ICD as opposed to only three times for those who had declined ICD. When stratified by race, this code was used 19 times among black participants, but only seven times among white participants.

In the following example, the participant describes that the ICD was a poor decision for him. He felt pressured into getting the procedure done and now regrets having had it placed.

"I'll tell you the truth: I was a little bit pressured into it... after I did it, I really didn't want it- I thought I made a bad decision, that I wish I hadn't done it." Black man with ICD

Participants expressed a lack of shared decision-making and described interactions with providers that were not collaborative. These descriptions included inadequate information given to patients or otherwise paternalistic interactions that left patients feeling that they did not have a choice.

One woman explained her negative experience in the following quote:

"When I asked him questions, I was shut down my whole time. I felt like I had no other choice, and that's why I ended up getting it." Black woman with an ICD

Alternatively, in the following quote, a man describes that he would do anything his doctor suggested because he trusted him so deeply. 
"Well, yeah, I mean, as far as past experiences, I've been with my cardiologist for 16 years and I just-I just told his nurse Monday, you know, if he told me to stand on my head 20 minutes a day and it would make my heart failure improve-I mean, now that's ridiculous, but if that's what he said to do, I would do it because that's the level of trust I have." White man with ICD

Aside from medical professionals, participants relied on others to help with the decisionmaking process. Collaborative decisions were made with the help of family or friends who had little to no medical background. Having had a support system in place to help make medical decisions about ICD placement was described 29 times among participants with ICD as opposed to only eight times for those who had declined ICD. Many of the female ICD accepters described relying upon family support for the ICD decision. Three participants expressed religious beliefs that helped them decide about getting an ICD placed, but most did not.

In the following quote, a woman explains the role her family played in deciding upon ICD implantation.

"We're such a close family...we decided that it was the best decision for us to get my heart back to where it needed to be." White woman with ICD

\section{DISCUSSION}

In this study, we developed an inductive qualitative framework to evaluate the views of patients meeting criteria for primary prevention ICD. Patients who have declined ICD expressed less personal benefit from ICD, did not view the ICD as positive or unrealistically curative, and had less decision support. We did not find that themes differed by race or sex. These findings help to shed light on the nuanced patient care interactions involved in ICD consideration. These findings are pertinent given the current mandate in the United States that providers dedicate time for shared decision-making prior to ICD implantation [26]. Shared decisionmaking between patients and medical providers incorporates patients' preferences and values, in light of their individual health conditions. The main benefit of this study is that it provides a foundation from which researchers and clinicians can improve the quality of shared decision-making regarding ICD implantation.

Though the recommendations for ICD implantation in this patient population are clear, the actual clinical decision-making for primary prevention is often fluid and nebulous. ICD implantation requires careful consideration of the risk-to-benefit ratio by the patient and physician [27]. Despite guidelines and national quality improvement initiatives, the low utilization rates for ICDs suggest a level of patient preference-sensitivity that has not been fully explored [28]. Such a nuanced decision-making process is unique for each patient, which makes our qualitative assessment an ideal method to examine the patient factors involved. This work adds a diverse perspective to the ICD decisionmaking literature because we purposefully included perceptions from women and black patients, groups that are often underrepresented in cardiovascular research.

Our findings are similar to those of Ottenberg et al., who studied the reasons why patients decline ICDs in a qualitative study of 13 patients. They identified that patients may benefit from enhanced education when deciding about ICD implantation [29]. However, our findings differed in that we found that HF symptoms were not necessarily associated with ICD acceptance. Most of our participants were symptomatic, yet eight continued to decline ICD implantation. This also differs from work by Balci et al. [30] who found that the misinformed goal of symptom relief was a main driver for ICD acceptance. Because our study also included participants who had declined ICD placement, we were able to show that the idea of symptom relief is only part of the decision.

Understanding the actual benefits of the ICD should be a main goal of informed decisionmaking. Some participants described feeling positively toward ICDs because their physicians were trustworthy or were otherwise persuasive. Notably, feeling persuaded is different from 
trusting in the physician. Blind, uninformed trust is not part of a collaborative, shared decision-making process. For non-accepting patients who understood the primary prevention ICD, many voiced concern that the device would not actually reverse their cardiomyopathy, thus lacking sufficient benefit.

Our study is not the first to show that patients with ICD overestimate the perceived benefits of ICD, are generally misinformed, and believe that the ICD would help cure HF. Qualitative studies with mostly white male patients with primary prevention ICDs showed that patients may not understand the benefits of ICD, and that cognitive biases may encourage ICD use for unsubstantiated benefits [31, 32]. Like others, we have identified gaps in patients' understanding and opportunities for providers to better educate patients $[29,32,33]$. In addition, we found that participants with more accurate understanding of ICD indications expressed a more in-depth shared decisionmaking process.

We found that patient concerns are not prohibitive of ICD acceptance. All of the ICD acceptors had agreed to ICD implantation despite their concerns, suggesting the importance of individualized discussion to address patient fears regarding living with an ICD. It is important to understand a patient's values and support system, as it may affect his or her decision to getting an ICD. We have shown that informed consent alone is not enough to properly educate a patient about the subtleties of ICD therapy and how it will benefit each individual patient.

\section{Limitations}

Our findings should be viewed in light of some limitations. Although our interview questions were previously vetted in a different patient population, we did not have an exhaustive list of ICD-specific questions. For example, we did not thoroughly assess specific barriers to informed consent and shared decision-making $[17,34]$. Similarly, we did not assess clinical aspects such as HF functional status, quality of life, or comorbidity. In addition, the open- ended questions were conducted over the phone and followed a long survey. Participant fatigue may have led to response brevity. On the other hand, the preceding survey was helpful in developing rapport prior to the in-depth interview. Also, we did not assess the providers' perspectives. However, our patients' perspectives were similar to those of clinicians that have been reported in the work of others $[33,34]$. Lastly, the data are cross-sectional in that the opinions of the ICD group and nonICD group are analyzed as being of different patient populations. However, some of the people who had not accepted an ICD at the time of this study may have gone on to accept an ICD later. This reflects the fluidity of the patient decision-making process and the importance of reassessment throughout the course of a patient's care. Furthermore, our participants with ICDs had undergone device implantation at a wide range of time points prior to this study, which potentially adds to the diversity of patient perspectives. Therefore, it is possible that responses could have been biased depending upon how long ago the ICD was implanted.

Given the small sample size, meaningful statistical conclusions are not possible in the current study. The lack of statistical analysis should not diminish the qualitative findings of this paper, the purpose of which was to elucidate patient perceptions of ICD acceptance. Subsequent work should test how shared decision-making and patient decision support could help clarify choices about ICD [22, 27]. The most updated guidelines for the prevention of sudden cardiac death support the use of shared decision-making [17]. Future guidelines will not only promote the role of shared decision-making but will also provide ways of measuring physician success at engaging patients in highquality decision-making processes [35]. Recently, a new performance measure was developed for ICDs. It emphasized the importance of measuring the rate of discussion about ICDs rather than the rate of ICD implantation [36]. Currently, a multicenter, randomized clinical trial is underway to assess the effectiveness of ICD patient decision aides. Based on the findings from the present study, clinicians 
should be inspired to think about how their interactions with patients affect clinical choices. Validated shared decision-making tools will eventually help support patients, families, and providers in pursuit of the best, most patientcentered care.

\section{CONCLUSIONS}

In this qualitative analysis, we demonstrate that patients who meet criteria for primary prevention ICD are symptomatic and want to live normal lives. ICDs are viewed by some ICD acceptors as a way to regain normal heart function. Those without ICDs perceive less personal benefit from ICDs. Decision support is important and can be achieved through shared decision-making. The informed consent process should explain the risks, benefits, and alternatives to ICD, but it is not sufficient to fully encapsulate the nuanced discussion many patients require.

The findings from our study emphasize the importance of decision-making with providers who are familiar and comfortable with discussing the patients' medical decision-making and preferences in light of possible positive or negative perceptions. Accepting ICD implantation requires informed consent and patient decision support that goes beyond the current communication patients receive.

\section{ACKNOWLEDGEMENTS}

Special thanks to Judy Chang, MD, and to the University Center for Social and Urban Research. The authors also wish to thank the study participants for their involvement in the study.

Funding. This study and the journal's rapid service fee were supported by the UPMC heart and Vascular Institute Cardiology Fellows' Grant Award; and the National Institutes of Health [Grant Number 1T32HL129964-1A1].

Authorship. All named authors meet the International Committee of Medical Journal
Editors (ICMJE) criteria for authorship for this article, take responsibility for the integrity of the work as a whole, and have given their approval for this version to be published.

Author Contributions. Amber Johnson: Conceptualization, Methodology, Formal analysis, Investigation, Data Curation, WritingOriginal Draft, Writing- Review \& Editing, Visualization, Project administration, Funding acquisition; Yamira Bell- Formal analysis, Writing- Original Draft Writing- Review \& Editing; Megan Hamm: Methodology, Formal analysis, Writing- Review \& Editing, Visualization; Samir Saba: Resources, Writing- Review \& Editing, Supervision; Larissa Myaskovsky WritingReview \& Editing, Supervision.

Disclosures. Dr. Myaskovsky's current affiliation is Department of Internal Medicine, University of New Mexico, School of Medicine, Albuquerque, NM, USA. Dr. Saba received research support from Boston Scientific and Abbott. Amber E. Johnson, Yamira K. Bell and Megan E. Hamm have nothing to disclose.

Compliance with Ethics Guidelines. The authors have received approval from the University of Pittsburgh institutional review board (PRO16050348). This study was performed in accordance with the Helsinki Declaration of 1964, and its later amendments. All subjects provided informed consent to participate in the study.

Data Availability. The datasets generated during and/or analyzed during the current study are not publicly available due to the qualitative nature of the patient interviews and the methodology in which the data were obtained, but are available from the corresponding author on reasonable request.

Open Access. This article is licensed under a Creative Commons Attribution-NonCommercial 4.0 International License, which permits any non-commercial use, sharing, adaptation, distribution and reproduction in any medium or format, as long as you give appropriate credit to the original author(s) and the source, provide 
a link to the Creative Commons licence, and indicate if changes were made. The images or other third party material in this article are included in the article's Creative Commons licence, unless indicated otherwise in a credit line to the material. If material is not included in the article's Creative Commons licence and your intended use is not permitted by statutory regulation or exceeds the permitted use, you will need to obtain permission directly from the copyright holder. To view a copy of this licence, visit http://creativecommons.org/licenses/by$\mathrm{nc} / 4.0 /$.

\section{REFERENCES}

1. Zipes DP, Wellens HJ. Sudden cardiac death. Circulation. 1998;98(21):2334-511.

2. Zheng ZJ, Croft JB, Giles WH, Mensah GA. Sudden cardiac death in the United States, 1989 to 1998. Circulation. 2001;104(18):2158-63.

3. Mozaffarian D, Benjamin EJ, Go AS, Arnett DK, Blaha MJ, Cushman M, et al. Executive summary: heart disease and stroke statistics-2016 update: a report from the American Heart Association. Circulation. 2016;133(4):447-54.

4. Moss AJ, Hall WJ, Cannom DS, Daubert JP, Higgins $\mathrm{SL}$, Klein $\mathrm{H}$, et al. Improved survival with an implanted defibrillator in patients with coronary disease at high risk for ventricular arrhythmia. Multicenter Automatic Defibrillator Implantation Trial Investigators. N Engl J Med. 1996;335(26): 1933-40.

5. Kadish A, Dyer A, Daubert JP, Quigg R, Estes NA, Anderson KP, et al. Prophylactic defibrillator implantation in patients with nonischemic dilated cardiomyopathy. N Engl J Med. 2004;350(21): 2151-8.

6. Lakshmanadoss U, Sherazi S, Aggarwal A, Hsi D, Aktas MK, Daubert JP, et al. Underutilization of implantable cardioverter defibrillator in primary prevention of sudden cardiac arrest. Cardiol Res. 2011;2(1):1-6.

7. Hernandez AF, Fonarow GC, Liang L, Al-Khatib SM, Curtis LH, LaBresh KA, et al. Sex and racial differences in the use of implantable cardioverter-defibrillators among patients hospitalized with heart failure. JAMA. 2007;298(13):1525-32.
8. Hess PL, Hernandez AF, Bhatt DL, Hellkamp AS, Yancy CW, Schwamm LH, et al. Sex and race/ethnicity differences in implantable cardioverter-defibrillator counseling and use among patients hospitalized with heart failure: findings from the get with the guidelines-heart failure program. Circulation. 2016;134(7):517-26.

9. Bank AJ, Gage RM, Olshansky B. On the underutilization of cardiac resynchronization therapy. J Cardiac Fail. 2014;20(9):696-705.

10. Zhang L, Narayanan K, Chugh H, Shiota T, Zheng ZJ, Chugh SS. Factors influencing utilization of the primary prevention implantable defibrillator. PLoS ONE. 2015;10(3):e0121515.

11. Pokorney SD, Miller AL, Chen AY, Thomas L, Fonarow GC, de Lemos JA, et al. Reassessment of cardiac function and implantable cardioverter-defibrillator use among Medicare patients with low ejection fraction after myocardial infarction. Circulation. 2017;135(1):38-47.

12. Patel NJ, Edla S, Deshmukh A, Nalluri N, Patel N, Agnihotri $\mathrm{K}$, et al. Gender, racial, and health insurance differences in the trend of implantable cardioverter-defibrillator (ICD) utilization: a United States experience over the last decade. Clin Cardiol. 2016;39(2):63-71.

13. Al-Khatib SM, Hellkamp AS, Hernandez AF, Fonarow GC, Thomas KL, Al-Khalidi HR, et al. Trends in use of implantable cardioverter-defibrillator therapy among patients hospitalized for heart failure: have the previously observed sex and racial disparities changed over time? Circulation. 2012;125(9):1094-101.

14. Randolph TC, Hellkamp AS, Zeitler EP, Fonarow GC, Hernandez AF, Thomas KL, et al. Utilization of cardiac resynchronization therapy in eligible patients hospitalized for heart failure and its association with patient outcomes. Am Heart J. 2017;189:48-58.

15. Mezu U, Ch I, Halder I, London B, Saba S. Women and minorities are less likely to receive an implantable cardioverter defibrillator for primary prevention of sudden cardiac death. Europace. 2012;14(3):341-4.

16. Johnson AE, Adhikari S, Althouse AD, Thoma F, Marroquin OC, Koscumb S, et al. Persistent sex disparities in implantable cardioverter-defibrillator therapy. Pacing Clin Electrophysiol. 2018;41(9): 1150-7.

17. Al-Khatib SM, Stevenson WG, Ackerman MJ, Bryant WJ, Callans DJ, Curtis AB, et al. 2017 AHA/ACC/ HRS Guideline for management of patients with ventricular arrhythmias and the prevention of 
sudden cardiac death: executive summary: a report of the American College of Cardiology/American Heart Association task force on clinical practice guidelines and the heart rhythm society. Circulation. 2018;138(13):e210-71.

18. Yancy CW, Jessup M, Bozkurt B, Butler J, Casey DE Jr, Drazner MH, et al. 2013 ACCF/AHA guideline for the management of heart failure: a report of the American College of Cardiology Foundation/ American Heart Association Task Force on practice guidelines. Circulation. 2013;128(16):e240-327.

19. Ponikowski P, Voors AA, Anker SD, Bueno H, Cleland JGF, Coats AJS, et al. 2016 ESC Guidelines for the diagnosis and treatment of acute and chronic heart failure: The Task Force for the diagnosis and treatment of acute and chronic heart failure of the European Society of Cardiology (ESC)Developed with the special contribution of the Heart Failure Association (HFA) of the ESC. Eur Heart J. 2016;37(27):2129-200.

20. Kilbourne AMSG, Hyman K, Crowley-Matoka M, Fine MJ. Advancing health disparities research within the health care system: a conceptual framework. Am J Public Health. 2006;96(12): 2113-211.

21. Ang DC, Monahan PO, Cronan TA. Understanding ethnic disparities in the use of total joint arthroplasty: application of the health belief model. Arthritis Rheum. 2008;59(1):102-8.

22. Green AR, Jenkins A, Masoudi FA, Magid DJ, Kutner JS, Leff $B$, et al. Decision-making experiences of patients with implantable cardioverter defibrillators. Pacing Clin Electrophysiol. 2016;39(10): 1061-9.

23. Lewis KB, Stacey D, Matlock DD. Making decisions about implantable cardioverter-defibrillators from implantation to end of life: an integrative review of patients' perspectives. The patient. 2014;7(3): 243-60.

24. Myaskovsky LFL. Understanding racial differences in preference for cadaveric versus living donor kidney transplantation. Pittsburgh, PA: Center for Health Equity Research and Promotion (CHERP), VA Pittsburgh Healthcare System (VAPHS). 2005.

25. Kuzel. Sampling in qualitative inquiry. In: Crabtree BMW (ed) Doing qualitative research. 3. Newbury Park, CA: Sage; 1982.

26. Decision memo for implantable cardioverter defibrillators (CAG-00157R4) https://www.cms.gov/ medicare-coverage-database/details/nca-decisionmemo.aspx?NCAId=288\#Top.
27. Allen LA, Stevenson LW, Grady KL, Goldstein NE, Matlock DD, Arnold RM, et al. Decision making in advanced heart failure: a scientific statement from the American Heart Association. Circulation. 2012;125(15):1928-52.

28. Matlock DD, Nowels CT, Masoudi FA, Sauer WH, Bekelman DB, Main DS, et al. Patient and cardiologist perceptions on decision making for implantable cardioverter-defibrillators: a qualitative study. Pacing Clin Electrophysiol. 2011;34(12): 1634-44.

29. Ottenberg AL, Mueller PS, Topazian RJ, Kaufman S, Swetz KM. "It's not broke, so let's not try to fix it": why patients decline a cardiovascular implantable electronic device. Pacing Clin Electrophysiol. 2014;37(10):1306-14.

30. Balci KG, Balci MM, Akboga MK, Sen F, Acar B, Yilmaz $S$, et al. Perceived benefits of implantable cardioverter defibrillator implantation among heart failure patients and its relation to quality of life: a cross-sectional study. Cardiol Therapy. 2015;4(2):155-65.

31. Matlock DD, Jones J, Nowels CT, Jenkins A, Allen LA, Kutner JS. Evidence of cognitive bias in decision making around implantable-cardioverter defibrillators: a qualitative framework analysis. J Cardiac Fail. 2017;23(11):794-9.

32. Stewart GC, Weintraub JR, Pratibhu PP, Semigran MJ, Camuso JM, Brooks K, et al. Patient expectations from implantable defibrillators to prevent death in heart failure. J Cardiac Fail. 2010;16(2): 106-13.

33. Hauptman PJ, Chibnall JT, Guild C, Armbrecht ES. Patient perceptions, physician communication, and the implantable cardioverter-defibrillator. JAMA Internal Med. 2013;173(7):571-7.

34. Zeuner R, Frosch DL, Kuzemchak MD, Politi MC. Physicians' perceptions of shared decision-making behaviours: a qualitative study demonstrating the continued chasm between aspirations and clinical practice. Health Expect. 2015;18(6):2465-76.

35. Lin GA, Matlock DD. Less patient-centered care: an unintended consequence of guidelines? JAMA Internal Med. 2013;173(7):578-9.

36. Bonow RO, Ganiats TG, Beam CT, Blake K, Casey DE Jr, Goodlin SJ, et al. ACCF/AHA/AMA-PCPI 2011 performance measures for adults with heart failure: a report of the American College of Cardiology Foundation/American Heart Association Task Force on Performance Measures and the American Medical Association-Physician Consortium for Performance Improvement. Circulation. 2012;125(19): 2382-401. 